\title{
A RELAÇÃO ENTRE LETRAMENTO LITERÁRIO EXTRA-ESCOLAR E CANÔNICO: UMA ANÁLISE CRÍTICO-DIALÓGICA
}

\author{
Marília Daniele Soares Vieira ${ }^{1}$ \\ André Luiz Frizon Faust ${ }^{2}$
}

\begin{abstract}
Resumo: O presente artigo trata da relação entre o letramento literário extra-escolar e as práticas de leitura obrigatórias na esfera escolar, através de análise de caso obtido por meio de entrevistas em profundidade, do tipo semi-aberta, realizadas numa escola da rede estadual, na grande Cuiabá. Nesse estudo de caso estão relatadas evidências da apropriação de discurso de As Crônicas de Gelo e Fogo em cartazes dos protestos de 2013, bem como a relação do aluno leitor e autor com seu professor de Língua Portuguesa, quem não encara a leitura do universo transmidiático de ficção fantástica norte-americana como prática letrada. A fim de embasar a análise de tais dados, serão contrastados os documentos oficiais atinentes às práticas de leitura e letramento literário - tais como os Parâmetros Curriculares Nacionais (PCN) e o Plano Nacional do Livro e Leitura (PNLL) - e conceitos obtidos através da promoção de diálogo entre aspectos teóricos discutidos pelos estudiosos Mikhail Bakhtin e Paulo Freire. Dessa maneira, objetiva-se alcançar a compreensão da função linguística de tais obras, bem como a relevância das práticas pessoais e individuais de leitura - sejam elas canônicas ou não - como parte constituinte da identidade do sujeito leitor. Retomando também o conceito de instrumentalização do texto como unidade de ensino da língua, independentemente de enquadramento literário ou rotulação editorial.
\end{abstract}

Palavra-chave: Letramento Literário, Práticas de Leitura, Cultura Pop, Transmídia

\begin{abstract}
This article is about the relationship between extracurricular literary literacy and the obligatory literary practice at school, made through a case study obtained using in-depth interview, of the semi-open kind, carried out in a public school of state level, in the metropolitan region of Cuiabá. In this case study are reported evidences of discourse appropriation from A Song of Ice And Fire in picket signs during 2013's protests, as well as the relationship between the reader-author student and his portuguese language teacher, that does not see as a literacy practice the reading of north-american fantastic fiction transmediatic universes. With the objective of laying the fundation for the analysis of such data, official documents relevant to reading practices and literary literacy — such as the National Curricular Parameters and the National Plan of Book and Reading - will be contrasted with concepts obtained through the promotion of dialogue between theoretical aspects discussed by the studious Mikhail Bakhtin and Paulo Freire. The objective is to reach a comprehension of the linguistic function of such works, as well as the relevance of individual and particular reading practices - being them canon or not — as a constituting part of the identity of the reader subject. Also recovering the concept of instrumentalization of the text as the language teaching unity, regardless of its literary framing or editoral branding.
\end{abstract}

\footnotetext{
${ }^{1}$ Mestrando pelo Programa de Pós-Graduação em Estudos de Linguagem da Universidade Federal de Mato Grosso (PPGEL - UFMT).

${ }^{2}$ Aluno especial na disciplina de Teorias do Discurso no Programa de Pós-Graduação em Estudos de Linguagem da Universidade Federal de Mato Grosso (PPGEL - UFMT).
} 
Keywords: Literary Literacy, Reading Practices, Pop Culture, Transmedia

\section{Introdução}

O presente artigo constitui-se como um desmembramento da pesquisa de mestrado intitulada, ainda provisoriamente, como A formação do leitor literário em ambientes extraescolares: quando o poder transformador de Guerra dos Tronos encontra a Muralha", conduzida no Programa de Pós-Graduação em Estudos de Linguagem da Universidade Federal de Mato Grosso, campus Cuiabá.

Naquela, tem-se por objetivo estudar e compreender a relação estabelecida entre as práticas de leitura escolares e extra-escolares de alunos dos anos finais da educação básica na rede pública, averiguando as possibilidades de promoção e manutenção de um ensino de bases dialógicas, que leve em consideração elementos de ambos os momentos na formação dos jovens sujeitos-leitores.

Para tanto, foram entrevistados sujeitos de diferentes estados do país, regularmente matriculados na rede pública de ensino em 2013, participantes dos protestos populares ocorridos no mesmo ano e neles identificados como leitores do universo transmidiático de As Crônicas de Gelo e Fogo.

Durante o período de coleta de dados da pesquisa, deparamo-nos com uma série de problemáticas novas, além de pequenas questões levantadas pelos próprios entrevistados que, infelizmente, não caberiam ser investigadas naquela pesquisa de mestrado.

Diante disso, optamos por explorar através deste artigo um dos casos relatados. Nele, o aluno identificado na pesquisa como Qhorin Meia-Mão ${ }^{3}$ descreve uma das atividades realizadas pelo professor de Literatura que, supostamente, contemplaria as propostas de ensino trazidas na pesquisa de mestrado, no entanto, não obtinha resultados positivos.

Assim sendo, optamos por buscar diretamente o professor, e com ele os dados e referencial necessários para a compreensão daquela prática e de seus resultados, bem como averiguar se seu insucesso enfraqueceria qualquer aspecto da hipótese estudada na pesquisa.

\section{O Corpus}

Graduado há mais de dez anos pelo Centro Universitário de Várzea Grande (UNIVAG), e há seis anos lotado numa mesma escola da Rede Pública Estadual de Mato Grosso, localizada na região central de Várzea Grande, área metropolitana de Cuiabá, o

\footnotetext{
${ }^{3} \mathrm{Na}$ referida pesquisa de mestrado, todos os sujeitos são identificados, por escolha própria e critérios não mencionados, através de nomes de personagens fictícios do universo de As Crônicas de Gelo e Fogo. $\mathrm{O}$ aluno em questão elegeu a personagem Qhorin Meia-Mão, membro importante da Patrulha da Noite.
} 
professor - identificado na pesquisa como Meistre Pycelle ${ }^{4}$ - assumiu a disciplina de Literatura ainda em seu segundo ano de trabalho.

Baseado em seu conhecimento empírico como professor de Língua Portuguesa acerca do desenvolvimento das atividades em sala, dos alunos e das práticas letradas dos mesmos, Pycelle pôde - segundo informou através de entrevista aberta - elaborar métodos próprios para o ensino de Literatura.

Diante de muitas dificuldades na execução de atividades que demandavam leitura, o professor decidiu implantar nas aulas de Literatura um modelo didático que - novamente, nas palavras do próprio professor - buscasse privilegiar o desenvolvimento da prática da leitura desses alunos.

Para tanto, foi desenvolvido um projeto que sugeria a leitura de dois livros ao longo do ano letivo - um durante o primeiro bimestre, outro durante o terceiro - bem como realização de duas atividades avaliativas. A primeira delas através de um sistema de avaliação escrita comum para o primeiro título, e a segunda através de encenações e seminários acerca do segundo título.

Numa negociação com as turmas A e B, do segundo ano do ensino médio de 2010, acordou-se que, o primeiro livro do projeto seria de escolha dos próprios alunos, enquanto que, o objeto dos estudos do segundo semestre seria escolha do professor.

\subsection{A Sequência Didática}

Como parte do acordo, os alunos das duas turmas sugeriram títulos, votaram e elegeram dois livros para o desenvolvimento da primeira etapa do projeto de leitura. Ao passo que o professor, de posse dos títulos, e orientando-se pelo modelo de Schneuwly (2004) desenvolveu uma sequência didática para o ensino de gêneros literários, identificação e categorização de obras literárias através de suas características ${ }^{5}$, para alunos do segundo ano do ensino médio.

Vale ressaltar que os textos-objetos e a sequência didática elaborada nunca foram substituídos ou reformulados, e é o desenvolvimento e o resultado da aplicação dessa sequência didática ao longo dos últimos cinco anos que constituem o corpus desta análise.

O modelo elaborado é composto por três etapas básicas. A primeira delas consiste numa apresentação dos dois títulos adotados, seguida pela etapa de leitura dos textos, e então uma etapa avaliativa. O diferencial da proposta seria, para o professor, a adoção de um gênero literário não-canônico, e o uso de títulos da comumente denominada Literatura Pop como unidade mínima de ensino da Língua e de Literatura.

\footnotetext{
${ }^{4}$ Seguindo a lógica de identificação da pesquisa de mestrado, o professor foi aqui nomeado como uma das personagens do universo de As Crônicas de Gelo e Fogo. Neste caso, o Meistre de Porto Real, por sugestão dos pesquisadores.

${ }^{5}$ Conforme consta nos dados obtidos através da análise dos diários, planos de aula e anotações fornecidos pelo próprio professor para a elaboração da presente pesquisa.
} 
Para tanto, a classe é inicialmente dividida, por critério de gênero, em dois grupos. Baseado nesse mesmo critério, o aluno recebia o título para leitura obrigatória, e realização de atividades ao longo do bimestre.

São eles Crepúsculo, primeiro volume da saga homônima, de autoria da estadunidense Stephanie Meyer, e Percy Jackson e o Ladrão de Raios, primeiro volume da saga Percy Jackson e Os Olimpianos, de Rick Riordan. O primeiro título cabe ao grupo composto exclusivamente por meninas, enquanto o segundo cabe ao grupo composto exclusivamente por meninos.

Após uma apresentação superficial dos enredos e a distribuição dos títulos, os mesmos são encaminhados para os alunos em arquivos de formato pdf $^{6}$ e se inicia a fase de leitura realizada em casa.

De modo a acompanhar o progresso dessa leitura - e numa tentativa de garantir a realização da atividade - Pycelle estabeleceu um cronograma que contém metas de leitura verificadas em reuniões quinzenais, ocupando os quinze minutos finais de sua aula. Nesses momentos, um aluno de cada grupo descreve a evolução da trama, e destaca um fato considerado relevante - segundo critérios não mencionados - nos capítulos programados para aquela etapa.

Neste momento, cabe salientar que tais reuniões são a única atividade de sala de aula, programada na sequência didática, que demanda a leitura dos títulos propostos. Enquanto que, as demais atividades correspondem, majoritariamente, à revisão dos conteúdos de Literatura Brasileira em sua divisão por escolas literárias.

Findado o prazo estipulado para a leitura dos títulos, os alunos recebem um questionário de auto-aplicação constituído por quatro blocos de perguntas. $\mathrm{O}$ primeiro deles demanda pesquisas acerca da ficha técnica de obra e autor, o segundo bloco é composto de questões acerca de características das personagens, o terceiro bloco demanda conhecimentos acerca do desenvolvimento do enredo e de fatos específicos da trama, e o último deles é constituído de perguntas acerca da existência de características que indicassem um possível enquadramento numa das escolas literárias abordadas nas aulas de revisão ${ }^{7}$.

Sobre as atividades avaliativas, elas são variáveis e costumam sofrer adaptações, conforme informou o professor durantes as entrevistas

Não dá tempo, esse povo não quer nada com nada... eu entreguei a prova e vieram 'Ah, Pycelle, não tem como responder isso aqui sem olhar no Google?'. Ai eu falei que podia olhar só aquela questão lá, e eles perguntaram 'cê vai pagar meu crédito?'. E eu ia falar o quê? Mandei pra casa pra ver se assim eles faziam. Mas nem assim... teve uns dois anos que nem pra ler o livro leram. Uma vez eu assisti os dois filmes, peguei umas imagens e perguntei na prova o que tava acontecendo naquela hora. Aí eles vieram dizer que não tinham assistido o filme. Pra cabá. Aí a gente larga de mão mesmo. (Entrevista realizada em 16 de junho de 2015)

\footnotetext{
${ }^{6}$ Portable Document Format.

7 É importante destacar que, a opção pela designação Escolas Literárias coube ao professor entrevistados, e não a estes pesquisadores.
} 


\section{Breve Análise}

Ainda nas análises mais superficiais dos dados fornecidos pelo professor Pycelle, um dos aspectos que mais nos chamou a atenção foi o rápido declínio da pontuação dos alunos nas avaliações efetuadas, além das indicações nos diários do professor, de uma vertiginosa queda de rendimento e produtividade dos alunos ao longo dos cinco anos documentados e analisados $^{8}$.

Motivados por essa percepção, buscamos aspectos que pudessem ajudar a compreender possíveis determinantes tanto para o sucesso inicial da proposta, quanto para seu declínio nos anos posteriores; bem como entender de quais maneiras esses aspectos se relacionam com as hipóteses levantadas pela pesquisa de mestrado que precede este artigo.

\subsection{Aspectos de sucesso}

Quando introduziu uma proposta inédita para os alunos de Literatura, ainda em 2010, o professor o fez de maneira a promover uma interação entre os grupos, de modo que os mesmos pudessem sugerir e escolher os livros que seriam lidos na primeira metade do ano letivo. A adoção dessa postura revelou-se um forte movimento de inclusão, uma vez que fez com que os alunos sentissem sua percepção do mundo ser valorizada, permitindo que se tornassem participantes ativos na elaboração do conteúdo com o qual interagiriam, ou seja, participantes ativos na construção de seu próprio conhecimento.

Da mesma maneira, ao empoderar os alunos através escolha dos textos, Pycelle abriu as portas da escola para que o universo do aluno o acompanhasse sala de aula a dentro. Logo, mesmo que - como professor de Literatura - não reconhecesse o mérito literário da cultura pop, nesta atitude acabou por reconhecer o mérito daquilo que é de interesse de seus alunos.

É nesse ponto que a prática de Pycelle e as proposta da pesquisa que precede este artigo se cruzam. Além da percepção e do reconhecimento dos interesses do aluno, o professor abandona a prática comum de rejeição de tais textos em detrimento ao cânone, empoderando o aluno ao imbricar os universos escolares e extra-escolares.

Porém, é nesse mesmo ponto que as duas propostas mais divergem. Apesar de parecer, a princípio, problemático lidar com o fato de uma ideia bem estruturada e fundamentada, executada de maneira muito similar ao longo de cinco anos, possa trazer resultados tão diferentes, essa estranheza se dá por ignorarmos que, para a cultura pop, um ano é tempo mais do que o suficiente para se construir e destruir um mesmo sucesso.

É exatamente a perda desse aspecto o fator que desencadeia o insucesso da prática. Pycelle, um professor acostumado a embasar teoricamente suas práticas, dispondo de um respeitável arcabouço teórico, peca ao desprezar o elemento humano de nossa profissão.

Enquanto o comércio - e a cultura pop - se adaptam às mudanças em seu mercado consumidor, o professor desprezou o elemento sobre qual se fundava o objeto de sua prática, e deixou de se adaptar às mudanças de seu mercado consumidor - por assim dizer.

\footnotetext{
${ }^{8}$ Conforme Tabela 1, em Anexos.
} 
Esse fato pode ser facilmente ilustrado utilizando a ferramenta de estatística do Google, denominada Google Trends, que revela a flutuação nas buscas de determinados termos ao longo do tempo. Apesar de não ser um dado definitivo ou conclusivo, esse mecanismo nos permite avaliar como a popularidade dos títulos escolhidos pela primeira turma de Pycelle eram altas no ano de 2010 e como, em pouco tempo, já em 2014, esses mesmos títulos haviam perdido grande parte de sua popularidade.

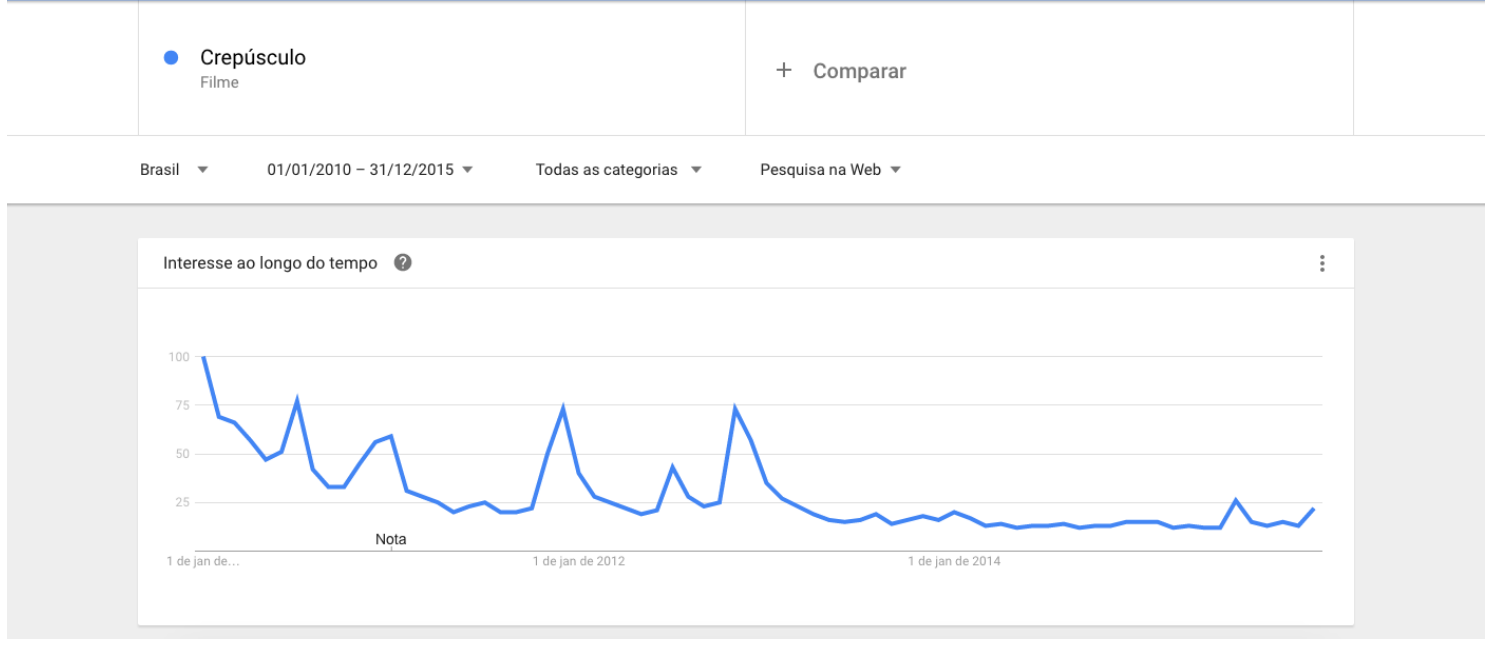

Buscas pelo termo "Crepúsculo" entre 01/01/2010 e 31/12/2015, revelando uma diminuição no interesse ao longo dos anos, apesar de alguns picos de popularidade até 2014.
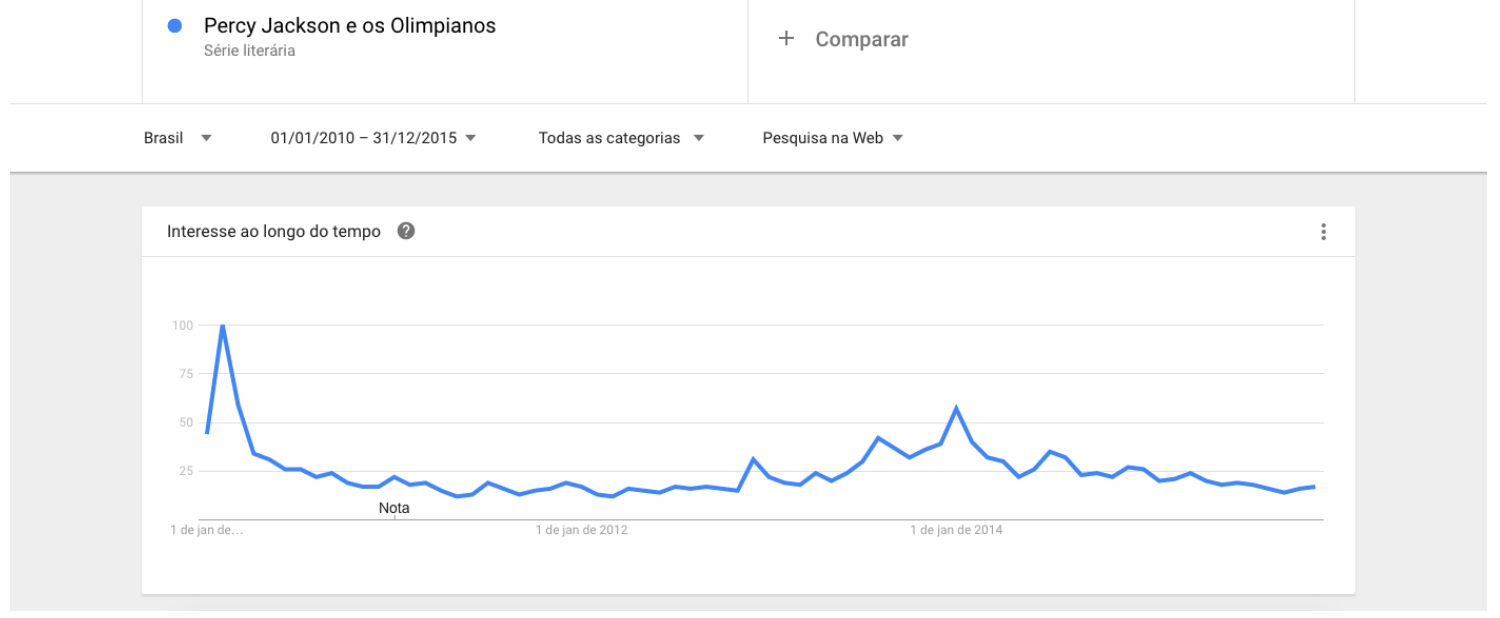

Buscas pelo termo "Percy Jackson e os Olimpianos" entre 01/01/2010 e 31/12/2015, revelando um interesse súbito no assunto no primeiro ano e uma grande queda em sua popularidade ainda no primeiro ano.

\subsection{Aspectos de insucesso}


No que tange as questões que, possivelmente, levaram ao insucesso da prática, podemos dividir a análise em dois momentos básicos, um de caráter teórico, que permeia a fundamentação teórica sobre a qual se aporta a sequência didática elaborada, bem como a execução da mesma, e outro intimamente ligado à necessidade do estabelecimento de práticas escolares mais dialógicas, pensadas não somente para o desenvolvimento de indivíduos críticos, como também objetivando a formação de sujeitos sociais.

Em virtude de partirmos de bases e orientações teóricas muito distintas das que fundamentam a formação do professor Pycelle, optamos por nos abster das discussões acerca da adoção de Sequência Didáticas segundo Scheneuwly. O que, no entanto, não impede que deitemos sobre o caso um olhar orientado pela perspectiva do Letramento Crítico.

Parece-nos relevante ressaltar que, a adoção de uma prática que muito se assemelha aos seminários, com a clara finalidade de verificação de leitura, ocupando um tempo espremido entre outras atividades, revela duas importantes nuances acerca do caso.

A primeira delas evidenciada na seguinte fala do professor, "isso que eles fazem na sala eu nem avalio, porque eles só vão e falam. Lá na hora da aula não dá pra prestar atenção pra dar nota" revela certa rejeição às práticas orais em detrimento da língua escrita, além de a excluir como aspecto da linguagem atinente à esfera escolar

Enquanto que, num segundo momento, demonstra a superficialidade com que o processo de leitura dos texto é abordado.

Segundo Rojo (2004), diferentes práticas letradas demandam capacidades de leitura como ao decodificação, a compreensão e as capacidades de interpretação e interação, no entanto, sob diferentes combinações. O que quer dizer que tais capacidades não são ativadas de modo encadeado ou ordenado, no entanto, constituem esse processo denominado Leitura, e precisam ser respeitadas.

O simples postar-se diante da classe para resumir o texto lido vai pouco além da exploração da capacidade de decodificação do texto. Enquanto que a falta de espaço para discutir os textos, além de não desenvolver a capacidade de interpretação e não ativar conhecimentos prévios, desestimula a interação entre sujeitos e, consequentemente, impede que se crie uma rede de intertextos.

Para Bakhtin (1934-35: 142), "o ensino das disciplinas verbais conhece duas modalidades básicas escolares de transmissão que assimila o [discurso de] outrem (do texto, das regras, dos exemplos): "de cór" e "com suas próprias palavras". No ambiente escolar, sobretudo no contexto aqui descrito, é comum que os vários discursos sejam palavras ditas de cór, sem processo de autoria, sem apropriação, mantendo-as coladas a voz do autor, como se ele proferisse um discurso original.

Estimular a interação dialogal na sala de aula, seja entre alunos ou dos mesmos com o professor, pode ser uma das mais ricas estratégias de construção do conhecimento, tendo em vista que, permite a troca de referências, a contraposição de opiniões e argumentos, e desdobramentos dos sentidos.

Segundo Bakhtin (1929), uma vez que somos seres sociais, o aprendizado é - e tem de ser - um processo dialógico. No entanto, é preciso ainda que essa perspectiva de dialogia resgate a alteridade, e que se compreenda que é na convivência com o outro que o ser se 
constitui. É na relação com o outro, e no pensamento do outro que nasce nosso próprio pensamento.

Assim sendo, limitar o processo de leitura de leitura a uma decodificação individual é limitar a construção do conhecimento e da identidade desses sujeitos. É, em alguma medida, desestimular a leitura crítica acerca do texto, do mundo e dos próprios indivíduos.

Avançando na análise, chegamos às questões que integram o questionário avaliativo, no entanto, mantém-se problemáticas da mesma ordem. Tal questionário, elaborado nos moldes das antigas fichas de leitura que acompanhavam os exemplares de clássicos da literatura, não levam o aluno a reflexão alguma. Mantém-se a mesma reprodução mecânica do texto decodificado.

Novamente, ainda que no contexto do texto que vem do universo do aluno, não há espaço para a voz do aluno, para suas palavras. E, tanto quanto não havia interação entre sujeitos, não há interação entre o aluno e o discurso, ou aluno e a língua.

Ao chegarmos ao quarto bloco do questionário, alcançamos aquelas questões supostamente - atinentes aos aspectos teóricos da atividade. Pensarmos na tentativa de identificação de características pré-estabelecidas pela crítica literária em obras contemporâneas poderia ser uma atividade de reflexão ou, retomando Rojo, que demandaria capacidades de compreensão. Tendo em vista que poderia conduzir à discussões acerca dos lugares sociais de onde falam os diferentes autores, nos diferentes momentos da literatura, e nas maneiras como tais questões transparecem nos textos.

No entanto, uma análise aprofundada das questões e das correções realizadas pelo professor demonstram que, ao invés de estimular tais discussões, Pycelle valia-se desse bloco do questionário para reforçar um estereótipo de inferioridade da literatura não-canônica em contraste com a canônica.

\section{Considerações Finais}

Numa esfera muito maior que as ideologias que transparecem na prática do professor, está o isolamento de ideias e sujeitos perpetrado por tal prática. Percebe-se um distanciamento gradativo entre os lugares sociais ocupados por professor e alunos, e na percepção dessas diferenças nunca postas em embates, reside o grande insucesso dessa prática.

Segundo Amorim:

$\mathrm{Na}$ estrada, os encontros inesperados acontecem. Esses encontros colocam em jogo, justamente, a possibilidade de mudança de estrada ou de rumo, e nisto reside, a nosso ver, o aspecto mais interessante desse cronotopos. É que ele é lugar por excelência de alteridade: o encontro com o outro traz em si a possibilidade de me desencaminhar.(2001, p.223)

Ao inviabilizar os embates, a relação dialógica que a construção do conhecimento exige, esse professor aleja não somente a formação de cada indivíduo em sua sala de aula, como também a sua própria.

Ao não se permitir desencaminhar, acaba por não permitir se constituir como sujeito, professor, em 2015. 


\section{Bibliografia}

AMORIM, M. O pesquisador e seu outro: Bakhtin nas ciências humanas. São Paulo: Musa Editora, 2001.

BAKHTIN, M. M. Marxismo e a Filosofia da Linguagem. 3. ed. São Paulo: Hucitec, 1929. M. M. O Discurso no Romance: Questòes de Literatura e estética. 3. ed. São Paolo: Hucitec, 1934

ROJO, R. Letramento e Capacidades de Leitura para a Cidadania. In: Anais do SEE: CENP, São Paulo, 2003. Disponível em: http://suzireis.bravehost.com/posgraduacao/artigos/roxane rojo.pdf. Acesso em: 15 dez. 2016.

SCHNEUWLY, B. \& DOLZ, J. Gêneros orais e escritos na escola, Campinas: Mercado de Letras, 2004.

\section{Anexos}

Tabela 1 - Média das notas dos alunos na atividade avaliativa do primeiro bimestre.

\begin{tabular}{llllll} 
& 2010 & 2011 & 2012 & 2013 & 2014 \\
\hline Meninas & 8,4 & 8,1 & 7,7 & 7,1 & 6,3 \\
\hline Meninos & 7,9 & 7,5 & 7,0 & 6,1 & 5,7 \\
\hline Trabalhos não entregues & $6 \%$ & $11 \%$ & $23 \%$ & $32 \%$ & $40 \%$ \\
\hline
\end{tabular}

